\section{Influence of Gases on the Rate of Evaporation of Water}

Two communications on this subject have been pub. lished recently. Sechrist ${ }^{1}$ found that water containing dissolved carbon dioxide, or surrounded by an atmosphere of this gas, evaporated $15-50$ per cent moro rapidly than water in the presence of air. Kingdon ${ }^{2}$ measured the rates of evaporation of water in the presence of 11 different gases, including hydrogen, oxygen, argon, carbon dioxide and butane. Rates varied over a range of 15 per cent in all gases except hydrogen and helium, which produced rates about 40 per cent less. Kingdon dofined a corrected rate of evaporation as the measured rate divided by the diffusion coefficient of water vapour in the surrounding gas. The corrected rate in butane was double that found in oxygen or nitrogen. Other gases also augmented the corrected rate relative to oxygen or nitrogen, except hydrogen or helium, which reduced it five-fold.

Both workers attributed their results to the influence of the gases on the physicochemical state of the water surface. Sechrist suggested that carbon dioxido catalyses the conversion of polymerized liquid water to single molecules, and Kingdon postulatod that some gases weaken hydrogen bonding at the water surface. Both these hypotheses imply that certain gases may raise the condensation coefficient of water vapour molecules at at water surface. The existing evidence suggests, however, that this coefficient may be unity ${ }^{3}$. Accordingly a further experiment seemed advisable.

In both the provious experiments the water was held within a shallow pan, so that water vapour migrated upwards from the surface. I have found that reversal of this direction reverses the trend of the observations.

A drop of water, volume $0.0070 \mathrm{ml}$., was generated at: tho tip of a thin glass tube attached to a micrometer syringe. The delivery tube was mounted in the rubber stopper of a flask which could be filled with a known dry gas. Rates of evaporation were readily measured by determining residual volumes after known intervals of time. With the flask standing on the bench so that water vapour migrated mainly downwards, drops evaporated 70 per cent more rapidly in hydrogen than in oxygen. In argon the rate was less than in oxygen by about 5 por cent, baroly significant in this work. These relative rates follow a trend opposite to that found by Kingdon. With the lask inverted, however, water evaporated 10 per cent more rapidly in argon and 50 per cent more slowly in hydrogen. Thus with water vapour migrating mainly upward results agroeing with Kingdon wore obtained.

It is coneluded that in all the reported experiments the relativo effects observed are influonced more by buoyancy than by any other factor. Whether the underlying mode of diffusion is viscous or turbulent, wator vapour departs from a water surface less rapidly if opposed gravitationally and more rapidly otherwise. Thus examination of Kingdon's measurements reveals a strong positive correlation betwen the density of the surrounding gas and the corrected rate of evaporation.

Kingdon also obscrved that evaporation proceeded spasmodically except when hindered by hydrogen ox helium, and suggested that the phenomenon arose from localized weakening of hydrogen bonds in the water surface. Spasmodic flow, however, is a common consequence of an unstable density gradient, and indeed has been observed within liquid water itself while evaporating ${ }^{4}$.

C.S.T.R.O. Division of Physical

W. W. MaNSTIETID

Chemistry,

Box 4331, G.P.O., Melbourne.

'Gechrist, F., Nature, 199, 899 (1963).

¿ Kingdon, K. H., J. Phys. Chem., 67, 2732 (1969)

sickman, K. C. D., Inilust. Ent. Chem, 46, 1442 (1054).

s spangenberg, W. G., and Rowland, W. R., Phisics of Fluids, 4, 743 (1901).

\section{Kinetics of Oxygen Reduction on the Amalgam - Acid Solution Interface}

IN earlier work on the kinetics of electrochemical corrosion on tho amalgam-acid solution interface, $I$ found on the basis of experiments carried out with the radioactive tracer method that the oxygen dissolved in the acid solution has a considerable offect on the electrochemical corrosion rate ${ }^{1,2}$. In the presence of dissolved oxygen the following part-processes occur during the corrosion of the amalgumated metal;

$$
\begin{gathered}
M e \rightarrow M e^{\nu+}+v e^{-} \\
\mathrm{O}_{2}+4 \mathrm{H}^{+}+4 e^{-} \rightarrow 2 \mathrm{H}_{2} \mathrm{O}
\end{gathered}
$$

As a result of these electrochemical part-processes a socalled mixed potential $(E M)$ develops on the amalgamacid solution interface ${ }^{3}$, where the dissolution velocity of the amalgamated metal equals the velocity of the oxygen reduction:

$$
\left(\frac{\mathrm{d} n}{\mathrm{~d} t}\right)_{1}^{E^{M}}=\left(\frac{\mathrm{d} n}{\mathrm{~d} t}\right)_{2}^{E^{M}}
$$

and the time profile of corrosion can be described by the following differential equation which is characteristic of a reaction of zero order:

$$
\left(\frac{\mathrm{d} n}{\mathrm{~d} t}\right)_{1}^{E^{u}}=k_{1}
$$

The following corrolation exists between tho specific rate constant and the half time of the reaction:

$$
k_{1}=\frac{C_{0}}{2 t_{1 / 2}}
$$

where $C_{0}$ is the initial concentration of the amalgam.

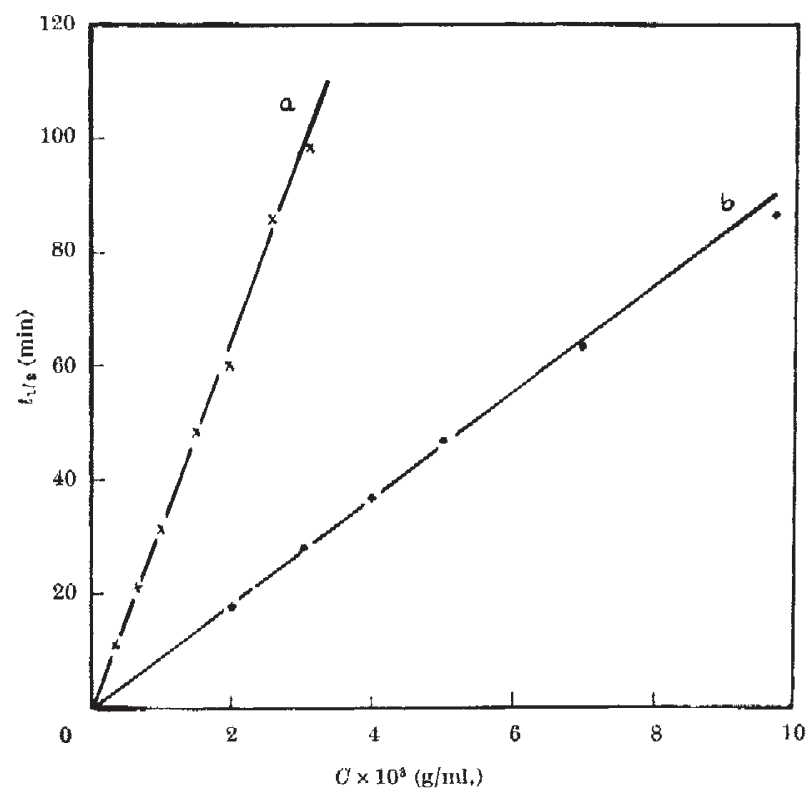

Hig. 1. Half-time of the corrosion process as a function of the initial concrintration of the amalgan. Temperature; 18 .
amalgam: $2 \mathrm{ml}$, (a) Zine amalgam; (b) thallum amalgam

Fig. 1 shows the half times of the corrosion of zinc amalgams tagged with ${ }^{65} \mathrm{Zn}$, and of thallium amalgam tagged with $201 \mathrm{Tl}$ of different concentrations, in a 0.01 $\mathrm{N} \mathrm{H}_{2} \mathrm{SO}_{4}$ solution saturated with air, as a finction of the initial concentration of the amalgam. The value of the rate constants was dotermined from the slope of the straight lins. Theso experiments support tho assumption that the diffusion of the dissolvod oxygen is a rate determining fictor in the corrosion of amalgans. The quantity of oxygen which reaches the unit surface of amalgam in unit time can be given by Fiek's lst law: 